\title{
PENGARUH PEMASANGAN ALAT PENINGKAT KUALITAS BAHAN BAKAR TERHADAP UNJUK KERJA DAN KONSUMSI BAHAN BAKAR SPESIFIK MOTOR BENSIN
}

\author{
Alim Kurnia Ismawan, Sunardi Wiyono, Nur Aklis \\ Jurusan Teknik Mesin Fakultas Teknik \\ Universitas Muhammadiyah Surakarta \\ Jl. A. Yani Tromol Pos I Pabelan, Surakarta \\ email:kurniaalim@yahoo.co.id
}

\begin{abstract}
ABSTRAK
Minyak merupakan Bahan bakar tidak dapat diperbaharui, karena itu, penghematan dan peningkatan kualitas bahan bakar minyak menjadi sesuatu yang sangat penting. Tujuan dari penelitian ini adalah untuk mengetahui pengaruh pemasangan alat peningkat kualitas bahan bakar terhadap torsi, daya dan konsumsi bahan bakar spesifik motor bensin. Penelitian ini dilakukan dengan membandingkan prestasi mesin motor bensin merk Yamaha Jupiter Z yang dipasang alat peningkat kualitas bahan baker merk Femax Combo dengan tanpa alat peningkat kualiatas bahan bakar. Setiap pengujian dilakukan pada putaran mesin 1500 rpm, 1750 rpm, 2000 rpm, 2250 rpm, 2500 rpm, 2750 rpm dan 3000 rpm. Hasil yang didapatkan dari analisa data adalah torsi dan daya pada pengujian menggunakan Femax Combo mengalami kenaikan dibandingkan dengan pengujian tanpa menggunakan Femax Combo. Sedangkan hasil analisa konsumsi bahan bakar spesifik dari pengujian menggunakan Femax Combo mengalami penurunan pada putaran mesin rendah dibandingkan dengan pengujian tanpa menggunakan Femax Combo. Akan tetapi pada putaran mesin tinggi, konsumsi bahan bakar spesifik pada pengujian menggunakan Femax Combo tidak mengalami penurunan yang signifikan dibandingkan dengan pengujian tanpa menggunakan Femax Combo.
\end{abstract}

Kata Kunci: alat peningkat kualitas bahan bakar, prestasi mesin

\section{PENDAHULUAN}

Bahan bakar minyak (BBM) berperan sangat penting dalam perkembangan teknologi, terutama dalam bidang teknologi industri dan otomotif. Penggunaan bahan bakar minyak semakin hari semakin meningkat. Padahal bahan bakar minyak merupakan sumber daya alam yang tidak dapat diperbaharui dan suatu saat akan habis. Kenaikan harga minyak mentah dunia yang mencapai titik tertinggi pada pertengahan tahun 2008 menghantam segala sendi perekonomian dan kehidupan masyarakat Indonesia. Selain itu, permasalahan mengenai kualitas bahan bakar yang kurang baik juga menimbulkan emisi gas buang yang buruk sehingga berbahaya bagi lingkungan.

Maka dari itu, melakukan penghematan bahan bakar minyak menjadi sesuatu yang sangat penting. Selain penghematan, memperbaiki kualitas bahan bakar minyak juga perlu dilakukan sehingga akan menghasilkan emisi gas buang yang ramah lingkungan. 
Salah satu cara yang digunakan untuk menghemat dan meningkatkan kualitas bahan bakar minyak adalah dengan penggunaan magnet. Alat peningkat kualitas bahan bakar minyak merk Femax Combo adalah suatu alat yang menggunakan medan magnet. Dengan pemberian medan magnet pada saluran bahan bakar diharapkan konsumsi bahan bakar akan berkurang dan menigkatkan kualitas bahan bakar, sehingga akan menghemat bahan bakar, menigkatkan prestasi mesin dan dapat mengurangi kadar emisi gas buang.

Masalah dalam penelitian ini, apakah dengan adanya alat peningkat kualitas BBM merk Femax Combo yang menggunakan megnet permanen pada saluran bahan bakar dapat meningkatkan kualitas bahan bakar menjadi semakin reaktif, sehingga dapat meningkatkan torsi dan daya, serta dapat menurunkan kebutuhan bahan bakar spesifik pada motor bensin.

\section{TINJAUAN PUSTAKA Kajian Pustaka}

Fitriadi (2006), telah melakukan penelitian mengenai pengaruh pemasangan magnet pada saluran bahan bakar motor bensin terhadap unjuk kerja dan konsumsi bahan bakar spesifik. Pada hasil penelitian didapatkan bahwa dengan adanya pemasangan magnet pada saluran bahan bakar motor bensin akan meningkatkan torsi dan daya, serta pemakaian bahan bakar menjadi semakin irit. Perbandingan antara menggunakan magnet dengan tanpa menggunakan magnet pada saluran bahan bakar motor bensin ada pengaruh yang signifikan sebesar 10\% untuk torsi, daya dan kebutuhan bahan bakar spesifik.

Ramadian (2007), melakukan suatu penelitian mengenai pengaruh pemasangan magnet pada saluran bahan bakar motor diesel terhadap konsumsi bahan bakar spesifik. Pada proses penelitian digunakan dua macam variabel percobaan, yaitu tanpa menggunakan magnet dan dengan menggunakan magnet pada saluran bahan bakar. Dari hasil penelitian didapatkan data percobaan yang dilakukan dalam waktu 1 jam untuk tiap kondisi (dengan dan tanpa magnet), konsumsi bahan bakar berkurang 30 lt/jam dengan produksi kWh yang sama, yaitu 0,08 $\mathrm{kWh}$. Dari hasil analisa, menggunakan magnet pada saluran bahan bakar dapat menurunkan konsumsi bahan bakar sebesar 5,45\% dari pemakaian normal tanpa menggunakan magnet.

Hariadi (2009), telah melakukan suatu penelitian mengenai pengaruh pemasangan alat Electrical Magnetic Resonance (EFT) terhadap konsumsi bahan bakar pada sepeda motor. Yang dimaksud dengan EFT adalah yang menggunakan metode menceraiberaikan material yang didalamnya mengandung hidrokarbon dengan induksi elektromagnetik, yang diharapkan ikatan antar molekul-molekul rantai hidrokarbon menjadi lebih renggang, sehingga pada saat proses pembakaran di ruang bakar mesin akan menjadi lebih sempurna. Dari hasil penelitian pada sepeda motor, 1 liter bensin menempuh jarak 50 km, setelah menggunakan EFT hasilnya 1 liter bensin mampu menempuh jarak $62 \mathrm{~km}$.

\section{Dasar Teori Motor Bensin}

Motor Otto atau Beau de Roches merupakan mesin pengonversi energi tidak langsung, yaitu dari energi kimia bahan bakar menjadi energi panas dan baru kemudian menjadi energi kinetik.

Berdasarkan siklus kerjanya, motor bensin dibedakan menjadi dua, yaitu :

a) Motor bensin dua langkah (Two Stroke) Motor bensin dua langkah adalah motor yang pada dua langkah piston (satu putaran poros engkol) sempurna akan menghasilkan satu langkah kerja.

b) Motor bensin empat langkah (Four Stroke) Motor bensin empat langkah adalah motor yang pada setiap empat langkah piston (dua putaran poros engkol) sempurna, menghasilkan satu tenaga kerja (satu langkah kerja).

Proses teoritis motor bensin adalah proses yang bekerja berdasarkan siklus Otto, dimana proses pemasukan kalor berlangsung pada volume konstan 


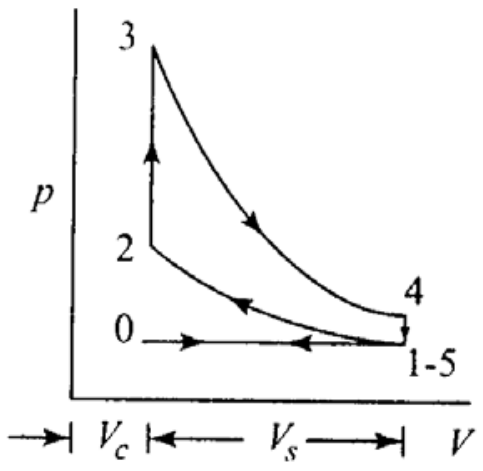

\section{Gambar 1. Siklus Teoritis Motor Bensin Empat Langkah}

Sedangkan siklus aktual yang terjadi pada motor bensin, efisiensinya jauh lebih rendah daripada efisiensi siklus teoritis, karena berbagai kerugian yang terjadi dalam operasi mesin.

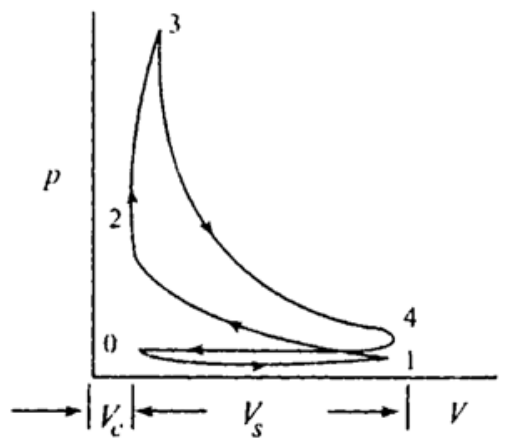

\section{Gambar 2. Siklus Aktual Motor Bensin Empat Langkah}

Sistem bahan bakar pada sepeda motor terdiri dari sistem suplai bahan bakar dan sistem penakar bahan bakar. Sistem suplai bahan bakar berfungsi mengalirkan bahan bakar dari tangki ke sistem penakar bahan bakar. Sedangkan sistem penakar bahan bakar berfungsi untuk menakar jumlah udara dan bahan bakar agar diperoleh campuran udara-bahan bakar yang dapat dibakar dengan cepat dan sempurna di dalam silinder dan juga berfungsi untuk atomisasi dan penyebar bahan bakar di dalam aliran udara.

\section{Dasar Teori Kemagnetan}

Macam-macam bahan ditinjau dari sifat kemagnetannya ada tiga macam, yaitu: a) Feromagnetik

Adalah bahan yang menimbulkan sifat kemagnetan yang kuat di bawah pengaruh medan magnet dari luar.

b) Paramagnetik

Adalah bahan yang menunjukkan sifat kemagnetan lemah dibawah pengaruh medan magnet dari luar.

c) Diamagnetik

Adalah bahan yang sedikit melawan pengaruh sifat kemagnetan dari pengaruh medan magnet dari luar.

\section{Dasar Teori Katalisator Bensin}

Cara kerja katalisator bensin adalah dengan menggunakan sistem kemagnetan, yaitu dengan pemberian suatu medan magnet pada saluran bahan bakar yang menuju karburator. Sebelum masuk ke ruang bakar, bensin mengalami restrukturisasi ion positif dan negatif agar lebih mudah terbakar di dalam silinder.

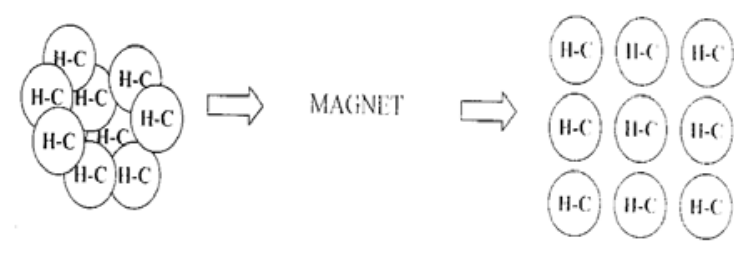

Gambar 3. Efek Kemagnetan

Molekul hidrokarbon merupakan unsur penyusun utama bensin, cenderung untuk saling tertarik satu sama lain, membentuk gugus molekul (clustering). Pemberian suatu medan magnet pada molekul hidrokarbon tersebut menyebabkan penolakan penolakan antar molekul hidrokarbon (declustering), sehingga terbentuk jarak yang optimal antara molekul hidrokarbon dan melemahkan ikatan antara atom $\mathrm{H}-\mathrm{C}$ dan mudah tertarik dengan oksigen pada proses pembakarannya.

Dengan adanya hal tersebut di atas, bahan bakar yang terkena efek kemagnetan akan menjadi semakin reaktif dalam proses pembakaran yang sempurna di ruang pembakaran, sehingga akan mempengaruhi unjuk kerja mesin yang semakin meningkat. 


\section{Prestasi Mesin}

Prestasi mesin adalah kemampuan mesin ditinjau dari daya dan torsinya terhadap putaran mesin. Selain itu akan dibahas mengenai konsumsi bahan bakar spesifik motor bensin.

a) Perhitungan Torsi

Torsi adalah perbandingan antara beban dan putaran poros mesin yang dapat dirumuskan sebagai berikut :

$$
\mathrm{T}=\frac{P .60}{2 \cdot \pi \cdot \mathrm{n}}
$$

dimana:

$$
\begin{array}{ll}
\mathrm{T} & =\text { Torsi (Nm) } \\
\mathrm{P} & =\text { Beban instalasi (Watt) } \\
\mathrm{n} & =\text { Putaran mesin (rpm) }
\end{array}
$$

b) Perhitungan Konsumsi Bahan Bakar Spesifik(KBBS)

Konsumsi bahan bakar spesifik adalah jumlah bahan bakar yang dibutuhkan untuk melakukan pembakaran tiap jam untuk menghasilkan satu satuan daya. Konsumsi bahan bakar spesifik dapat dihitung dengan rumus:

$\mathrm{KBBS}=\frac{m f}{\mathrm{P}}$

$$
m f=\frac{\mathrm{b}}{\mathrm{t}} \times \frac{3600}{1000} \times \rho_{b b}
$$

dimana:

KBBS = konsumsi bahan bakar spesifik (kg/jam.HP)

$M f \quad=$ Konsumsi bahan bakar (kg/jam)

$\mathrm{P} \quad=$ Daya (HP)

$\mathrm{B}=$ Volume buret yang dipakai dalam pengujian (cc)

$\mathrm{t}=$ Waktu pengosongan buret (s)

$\tilde{n}_{b b} \quad=$ Massa jenis bahan bakar bensin $(0,74 \mathrm{~kg} / \mathrm{l})$

\section{METODE PENELITIAN}

\section{Alat dan Bahan Penelitian}

Alat-alat pengujian yang digunakan :

a. Mesin bensin merk Yamaha Jupiter Z

b. Dinamometer Tecquipment Limited
c. Tachometer (digital) KOSO
d. Burret
e. Stopwatch

Spesimen uji yang digunakan dalam penelitian ini adalah alat peningkat kualitas BBM merk Femax Combo.

\section{Instalasi Pengujian}

Pemasangan alat uji dapat dilihat pada gambar 4 dan 5 sebagai berikut,

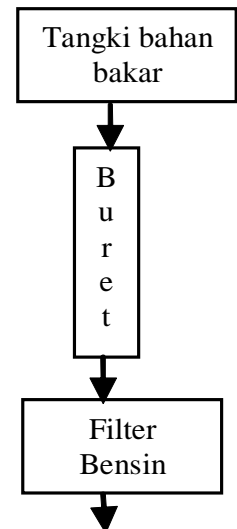

Alat peningkat kualitas BBM merk FEMAX combo

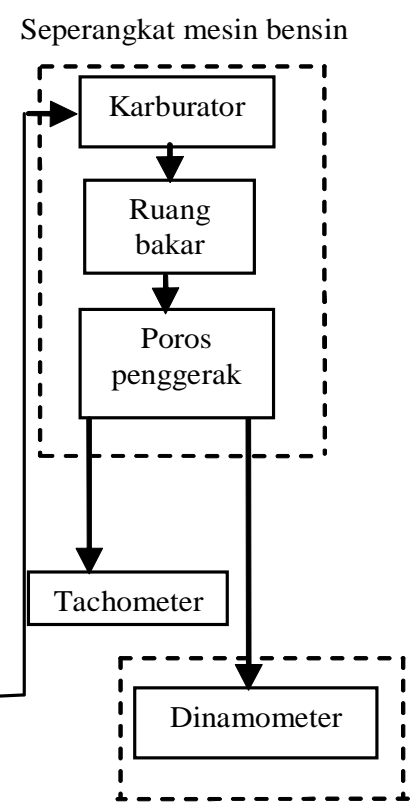

Pembebanan

\section{Gambar 7. Skema Instalasi}

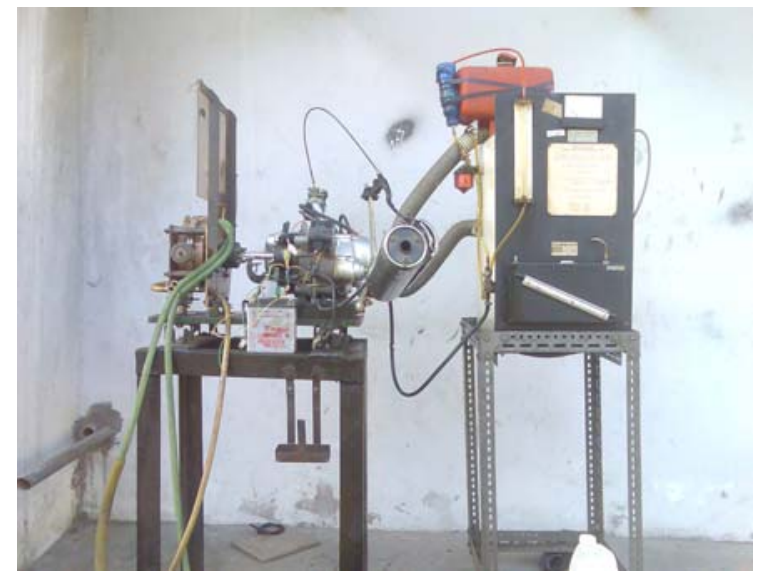

Gambar 5. Instalasi Pengujian 


\section{Alur Penelitian}

Gambar 6 menunjukkan diagram alir penelitian

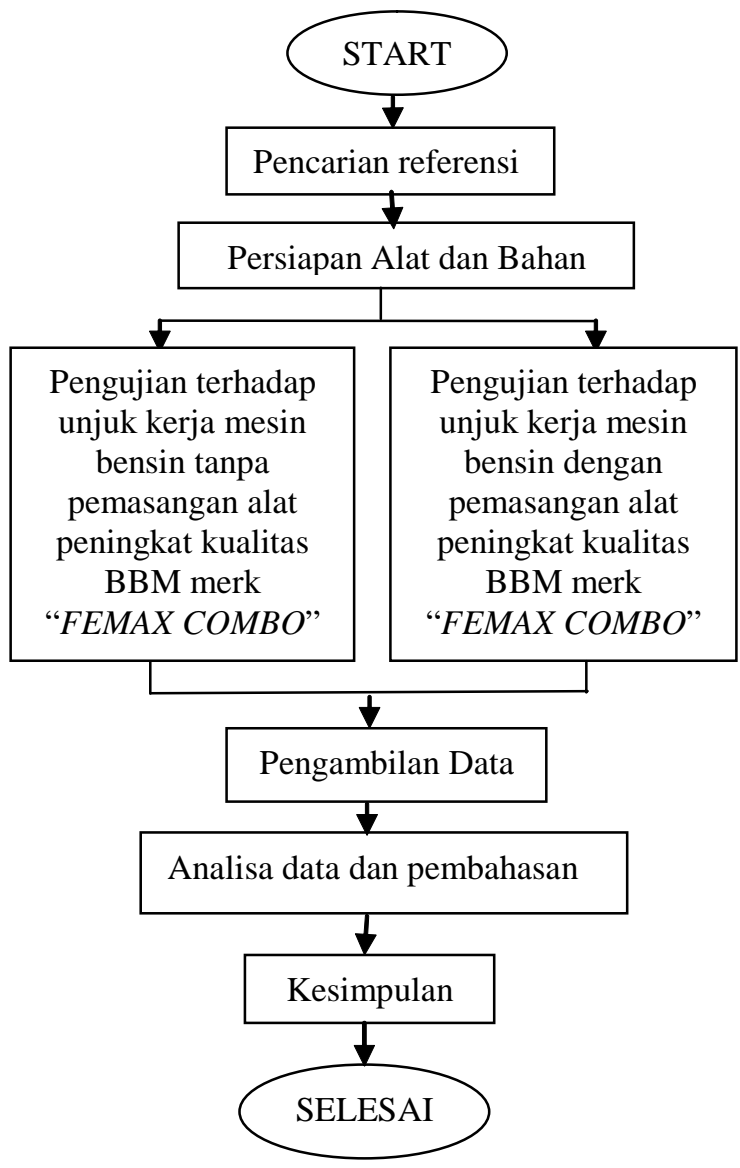

Gambar 6. Diagram Alir Penelitian

\section{HASIL DAN PEMBAHASAN}

Hubungan Putaran dengan Torsi

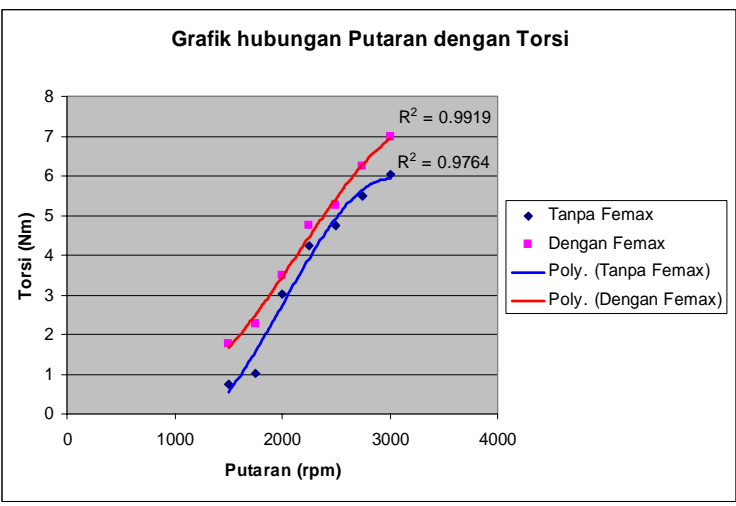

\section{Gambar 7. Grafik Hubungan Putaran dengan Torsi}

Gambar 7 menunjukkan hubungan antara putaran dengan torsi. Dari gambar dapat diketahui bahwa torsi yang dihasilkan perngujian yang menggunakan alat peningkat kualitas bahan bakar menunjukkan hasil yang lebih tinggi jika dibanding dengan percobaan tanpa menggunakan alat untuk setiap variasi putarannya.

Jika dibandingkan dengan grafik engine performa jenis motor bensin, kurva tanpa Femax Combo pada putaran 3000 rpm akan mencapai torsi pada titik maksimum, karena kurva cenderung untuk tidak naik lagi. Sedangkan pada kurva dengan Femax Combo, torsi pada putaran di atas $3000 \mathrm{rpm}$ masih ada kecenderungan untuk naik karena kurva belum mendekati torsi maksimum.

Hal ini terjadi karena pada putaran tinggi bahan bakar yang terkena efek kemagnetan alat dari karburator mengalir cepat ke ruang pembakaran, sedangkan posisi torsi maksimum bergantung pada efisiensi volumetris dan kerugiankerugian gesek pada ruang bakar. Dengan adanya pembakaran lebih sempurna, maka efisiensi volumetris akan meningkat dan kerugian kerugian gesek pada ruang bakar dapat berkurang, sehingga torsi yang dihasilkan akan naik.

\section{Hubungan Putaran dengan Daya}

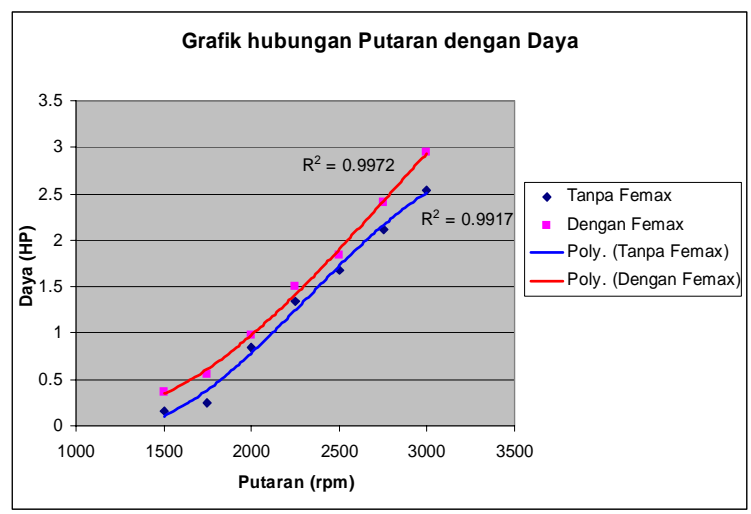

\section{Gambar 8. Grafik Hubungan Putaran dengan Daya}

Pada grafik gambar 8 dapat dilihat bahwa daya yang mampu dikerjakan mesin pada pecobaan menggunakan alat peningkat kualitas bahan bakar mengalami kenaikan dibandingkan 


\section{DAFTAR PUSTAKA}

Arends, BPM, Berenschot, H., 1980, Motor Bensin, Erlangga, Jakarta

Darsono, N., 2004, Studi Awal Pengaruh Magnetisasi Sistem Dipol Terhadap Komposisi Struktur Senyawa dan Indeks Refraksi serta Viskositas Kerosin, Pusat Penelitian Fisika Lembaga Ilmu Pengetahuan Indonesia, Tangerang

Fitriadi, A., 2006, Pengaruh Pemasangan Magnet Pada Saluran Bahan Bakar Terhadap Unjuk Kerja Motor Bensin, Universitas Muhammadiyah Surakarta, Sukoharjo

Ganesan, V., 2003, Internal Combustion Engines, $2^{\text {nd }}$ edition, Tata McGraw-Hill Publishing Co. Ltd., New Delhi

Hariadi, 2009, Menggunakan Alat Electric Fuel Treatment Bisa Hemat BBM, Lembaga Ilmu Pengetahuan Indonesia, Tangerang

Sudrajad, A., Hendratna, K.K., 2006, Menghemat Bahan Bakar dengan Magnet Portabel, Inovasi Online Vol 6/ XVIII/ Maret 2006, Tokyo

2005, Alat Penghemat BBM (hemat 30\%) Untuk Mobil dan Motor, Harian Republika, Edisi 20/ Januari/ 2005, Jakarta

, 2005, Katalisator Bensin Adu Hemat 3 Magnet, Majalah Otomotif, Edisi 39: XIV, 31/Januari/2005, Jakarta 